\title{
MARIA SANTOS-SAINZ, Albert Camus, journaliste - Reporter à Alger, éditorialiste à Paris
}

\section{Claudia Tedoldi}

\section{(2) OpenEdition}

\section{Journals}

\section{Edizione digitale}

URL: https://journals.openedition.org/studifrancesi/32193

DOI: 10.4000/studifrancesi.32193

ISSN: 2427-5856

\section{Editore}

Rosenberg \& Sellier

\section{Edizione cartacea}

Data di pubblicazione: 1 août 2020

Paginazione: 437-438

ISSN: 0039-2944

\section{Notizia bibliografica digitale}

Claudia Tedoldi, «MARIA SANTOS-saInz, Albert Camus, journaliste - Reporter à Alger, éditorialiste à Paris», Studi Francesi [Online], 191 (LXIV | II) | 2020, online dal 01 septembre 2020, consultato il 18 septembre 2021. URL: http://journals.openedition.org/studifrancesi/32193; DOI: https://doi.org/10.4000/studifrancesi. 32193

Questo documento è stato generato automaticamente il 18 septembre 2021.

\section{(c) $($ ) $(9)$}

Studi Francesi è distribuita con Licenza Creative Commons Attribuzione - Non commerciale - Non opere derivate 4.0 Internazionale. 


\title{
MARIA SANTOS-SAINZ, Albert Camus, journaliste - Reporter à Alger, éditorialiste à Paris
}

\author{
Claudia Tedoldi
}

\section{NOTIZIA}

MARIA SANTOS-SAINZ, Albert Camus, journaliste - Reporter à Alger, éditorialiste à Paris, Rennes, Éditions Apogée, 2019, 300 pp.

1 Il volume si propone come un manuale per giornalisti e futuri giornalisti. L'autrice Maria Santos-Sainz si avvale della figura di Albert Camus, al fine di presentarla come modello del mestiere. A tale scopo, viene raccontato il percorso biografico del giornalista franco-algerino in un insieme di sette capitoli, i quali coincidono con la ricostruzione puntuale della sua carriera di reporter presso diversi quotidiani dell'epoca. Ma non solo. Più si avanza nella lettura del testo più il profilo caratteriale $\mathrm{e}$ attitudinale dell'autore algerino si arricchisce, per merito di citazioni tratte dai personalissimi diari di Albert Camus, oppure grazie agli aneddoti emersi dalle dichiarazioni di amici e colleghi.

2 Nell'Introduzione («Aux futurs journalistes», pp. 15-24), Maria Santos-Sainz esprime la percezione che al giorno d'oggi il giornalismo sia subordinato al potere e che ci sia un diffuso senso di sfiducia nei confronti dei giornalisti e dell'autenticità della loro parola. Così l'A. invita il pubblico di giornalisti a prendere coraggio nell'esercizio della professione e a ritrovare dignità rispetto agli opportunismi e ai condizionamenti ideologici, misurandosi con il diritto al sapere e alla conoscenza. In questo senso, un'ulteriore volontà espressa nel libro è quella di fare luce sulla carriera giornalistica di Albert Camus, non ancora approfondita minuziosamente dalla critica camusiana.

3 Nella Prefazione (pp. 7-13), il giornalista francese Edwy PLENEL svela la natura dell'engagement di Camus, definendolo una forma di impegno etico, volto a difendere $\mathrm{i}$ 
valori umani e la dignità dell'individuo, denunciando ogni forma di ingiustizia e di barbarie moralmente deplorevoli. Un engagement esistenziale che si accorda con la libertà del singolo. Sull'onda del pensiero di Hannah Arendt, della quale rammenta Vérité et politique, emerge l'idea per cui un giornalista, seguendo le orme di Camus, dovrebbe ergersi a paladino scrupoloso della verità senza condizionamenti.

Maria Santos-Sainz individua alcuni repères biographiques della vita di Albert Camus, in modo particolare risalendo alle radici algerine, allinfanzia trascorsa in una terra inaridita dalla povertà, dalla miseria, ma nella quale è disseminata l'essenza del suo essere, oltre che della sua vocazione di scrittore. L'Algeria e la sua famiglia sono il punto focale della sua ispirazione poetica: rappresentano uno stile di vita, di pensiero, un'arte di vivere, una spiritualità, pur conservando i loro enigmi e le loro contraddizioni. Nella povertà è nascosto il senso vero dell'esistenza.

L'A. documenta, a questo punto, la prima esperienza lavorativa dello scrittore presso il quotidiano algerino "Alger républicain", estesasi dal 1938 al 1939 e per il quale il venticinquenne Camus scrive numerosi articoli, reportages, diverse inchieste che generano scalpore e fanno discutere. Certamente, però, a causa delle sue prese di posizione in difesa dei più deboli, contro le politiche illegali e i falsi ideologismi, Albert Camus disturba. Malvisto nella sua terra natale, egli deve scegliere la strada dell'esilio, raggiungendo Parigi nel 1940. Maria Santos-Sainz segue il cronologico corso degli eventi, delineando anche un excursus storico del Novecento. Albert Camus diventa ben presto giornalista di "Combat". Negli articoli redatti a Parigi denuncia in primo luogo lo stato di ineguaglianza fra i cittadini francesi d'Algeria e gli indigènes, oltre che l'inefficacia di una politica di assimilazione tra le due etnie, ma numerose sono le condanne dei totalitarismi e degli abusi di potere, oltre che gli articoli dedicati alla richiesta di una necessaria riforma della stampa. Albert Camus offre il suo ultimo contributo al giornalismo tra il 1955 e il 1956 per "l'Express". Durante gli anni della collaborazione con questo settimanale affronta di nuovo il problema dell'Algeria, riflette sul giornalismo e sulla libertà di espressione, si esprime contro il razzismo e la xenofobia e ritornano anche temi già affrontati durante gli anni di "Combat", quali il pacifismo, il rifiuto del nucleare, la fine delle ideologie.

6 Suggestive sono le citazioni tratte dai diari personali di Albert Camus, alle quali l'autrice si affida nella redazione dell'intero volume, al fine di avvalorare la propria documentazione e permettendo al lettore di avvicinarsi intimamente al pensiero del giornalista e scrittore, oltre che alla sua visione del mondo. Maria Santos-Sainz elabora, dunque, una sorta di manuale d'istruzione per giornalisti, ma che allo stesso tempo vuole essere un significativo contributo alla conoscenza della personalità di Albert Camus, oltre che del suo giornalismo all'insegna dell'onestà intellettuale, un giornalismo morale e militante. 